Analitika: Jurnal Magister Psikologi UMA, Vol. 12 (1) Juni (2020)

ISSN: 2085-6601 (Print), ISSN: 2502-4590 (Online)

DOI: http://dx.doi.org/analitika.v11i1.3079

\title{
Analitika
}

Jurnal Magister Psikologi UMA

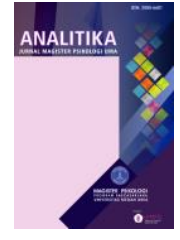

Available online http://ojs.uma.ac.id/index.php/analitika

\section{Coping Stress ditinjau dari Character Strength pada Klien di Loka Rehabilitasi BNN Deli Serdang}

\section{Coping Stress Based on Character Strength towards Rehabilitation Patients at BNN Deli Serdang}

\author{
Esti*, Yulinda Septiani Manurung, \& Sarinah \\ Program Studi Psikologi, Falkutas Psikologi, Universitas Prima Indonesia, Indonesia
}

Diterima: 11 November 2020, disetujui: 27 Juni 2020, dipublish: 30 Juni 2020

*Coresponding author: Email: estisu1979118@gmail.com

\begin{abstract}
Abstrak
Pasien yang berada di rehabilitasi narkoba sering merasa tertekan secara mental. Pemikiran yang seperti itu merujuk pada keadaan di mana para pecandu narkoba melakukan self-blame, karena itu penting bagi para pasien untuk mengatasi tekanan tersebut atau yang di namakan coping stress. Untuk merealisasi hal tersebut, diperlukan sikap positif yang terefleksikan dalam pikiran, perasaan dan tingkah laku pasein. Penelitian ini bertujuan untuk mengetahui hubungan antara character strength dengan coping stress. Subjek penelitian yang digunakan dalam penelitian ini adalah seluruh pasien di Loka Rehabilitasi BNN Deli Serdang, sebanyak 151 orang. Data diperoleh dari skala untuk mengukur character strength dan coping stress. Analisis data yang digunakan adalah menggunakan korelasi product moment melalui bantuan SPSS 17 for windows. Hasil analisis data menunjukkan koefisien korelasi sebesar $r=0,781$ dan nilai signifikansi sebesar $0.000(p<0.05)$. Ini menunjukkan ada hubungan positif antara character strength dengan coping stress. Hasil penelitian ini menunjukkan bahwa sumbangan yang diberikan variabel character strength terhadap coping stress sebesar 61,1 persen, selebihnya 38,9 persen dipengaruhi oleh faktor lain yang tidak diteliti. Berdasarkan hasil penelitian ini dapat ditarik kesimpulan bahwa hipotesis penelitian diterima, yaitu ada hubungan positif antara character strength dengan coping stress.
\end{abstract}

Kata kunci: Character Strength; Coping Stress; Klien Loka Rehabilitasi

\begin{abstract}
Patients who are in drug rehabilitation often feel mentally depressed. Such thinking refers to the circumstances in which drug addicts do self-blame. Therefore it is important for patients to cope with this pressure or what is called coping stress. To realize this, positive attitude is needed which is reflected in patient's thoughts, feelings and behavior. This study aims to determine the relationship between character strength and coping stress. Subjects used in this study were all 151 patients in Deli Serdang BNN Rehabilitation Workshop. Data obtained from a scale to measure character strength and coping stress. Data analysis used in this study is Pearson Product Moment through SPSS 17 for windows. The results of data analysis showed a correlation coefficient of $r=0.781$ and a significance value of $0.000(p<0.05)$. This shows that there is positive relationship between character strength and coping stress. The results of this study indicate that contribution given by character strength to coping stress is $61.1 \%$, the rest $38.9 \%$ is influenced by other factors not examined. Based on the results of this study it can be concluded that the research hypothesis is accepted, namely there is a positive relationship between character strength and coping stress.
\end{abstract}

Keywords: Character Strength; Coping Stress; Rehabilitation Patients

How to Cite: Esti, Yulinda, S.M., \& Sarinah. (2020). Coping Stress ditinjau dari Character Strength pada Klien di Loka Rehabilitasi BNN Deli Serdang. Analitika: Jurnal Magister Psikologi UMA, 12 (1): 55 - 63 


\section{PENDAHULUAN}

Penyalahgunaan narkoba di Indonesia telah menjadi ancaman nasional yang perlu diperhatikan secara seksama, baik ditinjau dari segi mikro (keluarga) maupun makro (ketahanan nasional). Hal ini semakin mengkhawatirkan dengan dampak buruk ekonomi dan sosial yang besar. Permasalahan penyalahgunaan dan peredaran gelap narkoba di Indonesia menunjukkan adanya kecenderungan yang terus meningkat, peningkatan yang terjadi tidak saja dari jumlah pelaku tetapi juga dari jumlah narkoba yang disita serta jenis narkoba.

Fakta peningkatan tersebut dapat dilihat dari data Badan Narkotika Nasional (BNN) yang dilansir Kompas (25/1/2012). Pemakaian narkoba pada tahun 2008 telah mencapai 3,6 juta jiwa, meningkat tahun 2011 menjadi 3,8 juta jiwa. Sementara jumlah kasus narkoba meningkat 23.531 kasus pada tahun 2010 menjadi 26.500 kasus di tahun 2011. Masih dari data yang sama, peredaran ekstasi dan sabu juga terus melonjak. Peredaran ekstasi naik 110 persen dari 371.197 tablet pada 2010 menjadi 780.885 tablet pada 2011, sedangkan sabu naik dari $283 \mathrm{~kg}$ pada 2010 menjadi 433 pada 2011. Begitu juga dengan data Komisi Nasional Perlindungan Anak, mencatat pasien ketergantungan narkoba di rumah sakit spesialis, yang mengalami kenaikan dari 2.090 jiwa pada 2009 menjadi 8.017 pada 2011.

Masuknya pengguna narkoba ke panti rehabilitasi memberi konsekuensi pentingnya melakukan coping stress. Hal ini selanjutnya tidak menjadi baik bagi pengguna narkoba yang berada di panti rehabilitasi karena adanya ketidaknyamanan yang dirasakan oleh pengguna narkoba itu sendiri dan dapat memunculkan berbagai pikiran negatif. Menurut (Stallard, 2005), pikiran-pikiran negatif yang sering muncul dapat menyebabkan stres. Sumber permasalahan berupa pola pikir yang negatif terhadap diri, lingkungan dan masalah yang dihadapi pada hakekatnya merupakan suatu ancaman bagi keberlangsungan hidup sehingga individu perlu mengantisipasinya. (Wicaksana, 2008) menambahkan bahwa kondisi stres dapat berlanjut menjadi gangguan mental dan perilaku, namun dapat pula tidak karena tergantung pada kuat lemahnya status mental atau kepribadian seseorang. Banyak kasus stres terjadi karena kurang mampunya individu menghadapi sumber stres ini.

Stres adalah pengalaman emosi negatif yang diikuti dengan perubahan biokimia, fisiologis, kognitif dan tingkah laku. Stres ini dapat dikategorikan sebagai tiga bagian, yaitu stimulus, respon, dan proses. Pendekatan yang mendefinisikan stres sebagai stimulus adalah pendekatan yang berfokus pada lingkungan. Pendekatan kedua meman dang stres sebagai respon. Pendekatan ini fokus kepada reaksi individu terhadap sumber stres. Pada pendekatan terakhir, stres dideskripsikan sebagai interaksi antara stimulus yang memicu stres dan diri individu sendiri (Brannon \& Feist, 2000). Dalam pengertian tersebut jelas 
perlu adanya strategi dalam menghadapi stres agar seseorang mampu melanjutkan hidupnya dengan sehat. Ketika individu mengalami stres seringkali tidak memiliki kemampuan mengatasi atau melakukan strategi dengan tepat, sehingga permasalahan yang dihadapi tidak mampu diselesaikannya.

Peneliti juga melakukan observasi dan wawancara pada salah satu pusat rehabilitasi narkoba di Lubuk Pakam dan menemukan bahwa pasien-pasien juga sering merasa tertekan secara mental. Rata-rata pasien menyatakan bahwa mereka ingin berubah menjadi pribadi yang lebih baik, namun dorongan untuk menggunakan obat-obatan terlarang tersebut juga sering menghantui mereka. Dilema yang dirasakan juga menimbulkan respon yang berbedabeda. Tidak jarang ada pasien yang histeris, menangis dan memberontak. Sebagian pasien menyatakan diri mereka takut akan stigma masyarakat terhadap mereka. Rasa takut tersebut terbayang-bayang dan meresahkan mereka. Pasien-pasien tersebut mengatakan bahwa jika dirinya merasa tenang apabila orang-orang di sekitarnya menyemangatinya, namun menurut mereka hal tersebut tidaklah mudah didapatkan di masyarakat. Kondisi yang seperti itu, tatkala membuat mereka sedih dan semakin meratapi nasibnya sebagai pecandu narkoba.

Dalam (Chaplin, 2002), coping stress diartikan sebagai sembarang perbuatan, dalam mana individu melakukan interaksi dengan lingkungan sekitarnya, dengan tujuan menyelesaikan sesuatu (tugas atau masalah). Lazarus dan Folkman dalam (Sarafino \& Smith, 2008) mengartikan coping stress adalah suatu proses dimana individu mencoba untuk mengatur kesenjangan persepsi antara tuntutan situasi yang menekan dengan kemampuan mereka dalam memenuhi tuntutan tersebut.

Salah satu faktor yang mempengaruhi coping stress adalah character strength. Hal ini sejalan dengan penelitian oleh (Won, 2011) pada para remaja di Korea yang mengungkap bahwa character strength berpengaruh signifikan terhadap adaptive coping styles. Menurut Park, dkk., (Simmons, 2012), character strength didefinisikan sebagai sifat positif yang terefleksikan dalam pikiran, perasaan dan tingkah laku. Sementara (Polly \& Britton, 2015) menyatakan character strength sebagai komponen kehidupan yang baik. Karakter seseorang perlahan-lahan terbentuk seiring berjalannya waktu, setiap kali individu menghadapi pengalaman hidup yang berbeda-beda. Setiap pengalaman hidup tersebut memerlukan dan mengembangkan character strength. Hal-hal seperti keberanian untuk tinggal terpisah dari orang tua, kontrol diri untuk bekerja dan bertingkah laku sopan, kerendahan diri untuk membina hubungan dengan orang lain, menjadi orang tua yang bijaksana adalah contoh dari pengalaman hidup yang umumnya dihadapi seseorang (Greenstein \& Holland, 2014). 
Menurut (Kim et al., 2016) dengan menggunakan Adopted Inventory of Virtues and Strengths (AIVS) Scale, terdapat lima aspek yang mempengaruhi pengukuran character strenght, yaitu: Emotional transcendence $(\alpha=0,84)$, Integrity $(\alpha=$ $0,78)$, Courage $(\alpha=0,77)$, Commitment to action $(\alpha=0,78)$.

Hubungan antara character strength dengan coping stress dipertegas hasil penelitian (Harzer \& Ruch, 2015). Berdasarkan penelitian tersebut, diketahui bahwa orang-orang yang memiliki rasa keingintahuan yang tinggi dan cara berpikir yang kreatif (intellectual strengths), berani, gigih, berpengharapan dan memiliki wawasan luas (emotional strengths), serta memiliki kemampuan dalam membangun hubungan interpersonal yang baik (interpersonal strengths) adalah orang-orang yang memiliki kemampuan coping stress yang baik. Hasil penelitian tersebut menunjukkan bahwa ada character strength memiliki hubungan positif terhadap coping stress. Artinya semakin baik character strength, maka semakin baik pula coping stress.

Peneliti juga melakukan observasi dan wawancara pada salah satu pusat rehabilitasi narkoba di Lubuk Pakam dan menemukan bahwa pasien-pasien juga sering merasa tertekan secara mental. Rata-rata pasien menyatakan bahwa mereka ingin berubah menjadi pribadi yang lebih baik, namun dorongan untuk menggunakan obat-obatan terlarang tersebut juga sering menghantui mereka. Dilema yang dirasakan juga menimbulkan respon yang berbedabeda. Tidak jarang ada pasien yang histeris, menangis dan memberontak. Sebagian pasien menyatakan diri mereka takut akan stigma masyarakat terhadap mereka. Rasa takut tersebut terbayang-bayang dan meresahkan mereka. Pasien - pasien tersebut mengatakan bahwa jika dirinya merasa tenang apabila orang - orang di sekitarnya menyemangatinya, namun menurut mereka hal tersebut tidaklah mudah didapatkan di masyarakat. Kondisi yang seperti itu, tatkala membuat mereka sedih dan semakin meratapi nasibnya sebagai pecandu narkoba.

Berdasarkan penjelasan yang disampaikan di atas, maka peneliti ingin meneliti lebih lanjut tentang coping stress, serta keterkaitannya dengan character strength yang dimiliki seseorang dalam suatu penelitian yang berjudul, "Coping Stress Ditinjau dari Character Strength pada Klien Rehabilitas di Loka Rehabilitasi BNN Deli Serdang."

\section{METODE PENELITIAN}

Penelitian ini menggunakan metode penelitian kuantitatif dengan teknik analisis korelasional. Populasi dalam penelitian ini adalah seluruh pasien di Loka Rehabilitasi BNN Deli Serdang yang berjumlah 176 orang. Teknik pengambilan sampel yang digunakan adalah sampling jenuh, yaitu teknik penentuan sampel bila semua anggota populasi digunakan sebagai sampel (Sugiyono, 2010).

Pengumpulan data coping stress dan character strength menggunakan 
skala pengukuran yang disusun oleh peneliti. Coping stress adalah dimana seseorang yang mengalami stres atau ketegangan psikologis dalam menghadapi masalah kehidupan sehari-hari yang memerlukan kemampuan pribadi maupun dukungan dari lingkungan, agar dapat mengurangi stres yang dihadapinya. Skala coping stess yang terdiri dari 42 aitem disusun berdasarkan Pengukuran yang dilakukan (Smith et al., 1995) dengan menggunakan Athletic Coping Stress Inventory-28 (CSAI-28) memiliki koefisien Alpha Cronbach sebesar 0,86 dan terdiri dari tujuh faktor, yaitu sebagai berikut: (a) Coping with adversity $(\alpha=0,66)$, (b) Peaking under pressure $(\alpha=0,78),(c)$ Goal setting/mental preparation $(\alpha=$ $0,71)$, (d) Concentration $(\alpha=0,62),(\mathrm{e})$ Freedom from worry $(\alpha=0,76)$, (f) Confidence and achievement motivation $(\alpha=0,66)$, dan (g) Coachability $(\alpha=$ 0,72 ). Bedasarkan uji reliabilitas skala coping stress ini diperoleh koefisien reliabilitas Alpha Cronbach sebesar 0,885 . Hal ini berarti bahwa skala ini layak digunakan sebagai alat pengumpulan data dalam penelitian ini.

Character strength menurut (Peterson \& Seligman, 2004) mendefinisikan character strength sebagai bahan psikologis, proses atau mekanisme, yang menjelaskan tentang virtues. Dengan kata lain, character strength adalah rute yang bisa dibedakan untuk memperlihatkan satu atau lebih virtue. Sebagai contoh virtue of wisdom dapat dicapai melalui strength seperti creativity, curiosity, love of learning, open mindedness, dan apa yang disebut sebagai perspective. Jadi dapat dikatakan bahwa character strength adalah trait positif yang terdiri dari karakter yang baik. Adapun skala character strength yang terdiri dari 40 aitem. disusun berdasarkan Pengukuran yang dilakukan oleh (Kim et al., 2016) dengan menggunakan Adopted Inventory of Virtues and Strengths (AIVS) Scale, yang terdiri dari lima faktor, yaitu: Emotional transcendence $(\alpha=0,84)$, Practical wisdom $(\alpha=0,78)$, Integrity $(\alpha=0,78)$, Courage $(\alpha=0,77)$, Commitment to action $(\alpha=0,78)$. Bedasarkan uji reliabilitas skala character strength ini diperoleh koefisien reliabilitas Alpha Cronbach sebesar 0,864. Hal ini berarti bahwa skala ini layak digunakan sebagai alat pengumpulan data dalam penelitian ini.

Sebelum dilakukan pengujian hipotesis dengan Pearson Product Moment Correlation, terlebih dahulu dilakukan uji asumsi Sebelum dilakukan pengujian hipotesis dengan Pearson Product Moment Correlation, terlebih dahulu dilakukan uji asumsi klasik meliputi uji normalitas sebaran dengan rumus Kolmogorov Smirnov Z dan uji linearitas hubungan dengan linearity test.

\section{HASIL DAN PEMBAHASAN}

Hasil deskripsi data dalam penelitian ini mencakup skor empirik dan skor hipotetik. Skala coping stress terdiri dari 29 aitem dengan skor aitemnya yang bergerak dari empat pilihan jawaban dengan skor satu sampai empat. Rentang minimum dan 
maksimumnya adalah $29 \times 1$ sampai 29 x 4, yaitu 29 sampai 116 dengan mean hipotetiknya $(116+29): 2=72,5$. Standar deviasi hipotetik dalam penelitian ini adalah $(116-29): 6=14$, 5. Dari skala coping stress yang diisi subjek, maka diperoleh mean empirik sebesar 79, 79 dengan standar deviasi 11,306. Perbandingan data empirik dan data hipotetik dapat dilihat pada Tabel 1.

Tabel 1

Perbandingan Data Empirik dan Data Hipotetik Coping stress

\begin{tabular}{ccccc}
\hline Variabel & \multicolumn{3}{c}{ Empirik } & SD \\
& Min & Max & Mean & \\
\cline { 2 - 4 } Coping & 31 & 113 & 85,21 & 12,206 \\
\cline { 2 - 4 } stress & \multicolumn{3}{c}{ Hipotetik } & SD \\
\cline { 2 - 4 } & Min & Max & Mean & \\
\cline { 2 - 4 } & 29 & 116 & 72,5 & 14,5 \\
\hline
\end{tabular}

Apabila mean empirik >mean hipotetik maka hasil penelitian yang diperoleh akan dinyatakan tinggi, dan sebaliknya jika mean empirik <mean hipotetik maka hasil penelitian akan dinyatakan rendah. Hasil analisis untuk skala coping stress diperoleh mean empirik > mean hipotetik yaitu $85,21>72,5$, maka dapat disimpulkan bahwa coping stress subjek penelitian lebih tinggi daripada populasi pada umumnya.

Selanjutnya subjek akan dibagi ke dalam tiga kategori coping stress, yaitu coping stress rendah, sedang dan tinggi. Pengkategorian coping stress dengan membagi distribusi normal ke dalam tiga bagian standar deviasi; kategori rendah, $x<(\mu-1,0 \sigma)$; kategori sedang, $(\mu-1,0 \sigma) \leq \mathrm{x}<(\mu+1,0 \sigma)$; kategori tinggi, $x \geq(\mu+1,0 \sigma)$.
Tabel 2

Kategorisasi Coping stress

\begin{tabular}{ccccc}
\hline \multirow{2}{*}{ Variabel } & $\begin{array}{c}\text { Rentang } \\
\text { Nilai }\end{array}$ & Kategori & $\begin{array}{c}\text { Jumlah } \\
\text { (n) }\end{array}$ & Persentase \\
\hline \multirow{3}{*}{$\begin{array}{c}\text { Coping } \\
\text { stress }\end{array}$} & $\begin{array}{c}\mathrm{x}<58 \\
\mathrm{8} \leq \mathrm{x}<\end{array}$ & Rendah & 1 & $0,66 \%$ \\
\cline { 2 - 5 } & $\mathrm{x} \geq 87$ & Tinggi & 78 & $51,66 \%$ \\
\hline & Jumlah & & $\mathbf{1 5 1}$ & $\mathbf{1 0 0 \%}$ \\
\hline
\end{tabular}

Pada Tabel 2 dapat dilihat bahwa terdapat 1 subjek yang mengalami coping stress rendah atau 0,66 persen, subjek yang mengalami coping stress sedang adalah sebanyak 72 orang atau 47,68 persen, dan subjek yang mengalami coping stress tinggi adalah sebanyak 78 orang atau 51,66 persen.Berdasarkan penjelasan di atas maka dapat disimpulkan bahwa ratarata subjek penelitian memiliki tingkat coping stress yang tinggi.

Uji normalitas dilakukan agar dapat mengetahui apakah setiap variabel penelitian telah menyebar secara normal atau tidak. Uji normalitas sebaran menggunakan uji Kolmogorov Smirnov Test. Data dikatakan berdistribusi normal jika $\mathrm{p}$ > 0,05 (Nazir, 2003). Uji normalitas yang dilakukan terhadap variabel coping stress koefisien $\mathrm{KS}-\mathrm{Z}=0,922$ dengan sig sebesar 0,364 untuk uji 2 (dua) arah, sedangkan penelitian ini memiliki hipotesis satu arah, sehingga yang dipakai adalah uji 1 (satu) ekor/ sig 1tailed sebesar 0,182 ( $p>0,05)$, yang berarti bahwa data pada variabel peneyesuaian diri memiliki sebaran atau berdistribusi normal. Uji normalitas pada variabel character strength diperoleh koefisien KS-Z = 1,086 dengan Sig sebesar 0,189 untuk uji 2 (dua) arah dan sig sebesar 0,0945 
untuk uji 1 (satu) arah ( $\mathrm{p}>0,05)$, yang berarti bahwa data pada variabel character strength sebaran atau berdistribusi normal. Hasil uji normalitas dapat dilihat pada Tabel 3.

Tabel 3

Hasil Uji Normalitas

\begin{tabular}{lllll}
\hline Variabel & SD & KS-Z & Sig. & P \\
\hline $\begin{array}{l}\text { Coping } \\
\text { stress }\end{array}$ & 12,206 & 0,922 & 0,182 & $\mathrm{p}>0,05$ \\
\hline $\begin{array}{l}\text { Character } \\
\text { Strength }\end{array}$ & 10,201 & 1,088 & 0,0945 & $\mathrm{p}>0,05$ \\
\hline
\end{tabular}

Uji linieritas digunakan untuk mengetahui apakah distribusi data penelitian yaitu variabel coping stressdan character strength memiliki hubungan linier Uji F (Anova).Menurut Sugiyono (2010), jika $\mathrm{p}<0,05$ maka hubungan antara kedua variabel yaitu coping stress dan character strength dikatakan linier. Hasil uji linieritas dapat dilihat pada Tabel 4.

Tabel 4.

Hasil Uji Linearitas Hubungan

\begin{tabular}{lcl}
\hline Variabel & F & Sig \\
\hline Coping stress & 249,645 & 0,000 \\
Character strength & & \\
\hline
\end{tabular}

Berdasarkan hasil analisis korelasi antara character strength dengan coping stress, diperoleh koefisien korelasi product moment sebesar 0,783 dengan sig sebesar 0,000 $(\mathrm{p}<0,05)$. Hal ini menunjukkan bahwa adanya korelasi positif antara character strength dengan coping stress sehingga dikategorikan hubungan yang kuat (Arikunto, 2010). Dari hasil perhitungan tersebut, maka hipotesis yang diajukan dalam penelitian ini menunjukkan ada hubungan positif antara character strength dengan coping stress diterima, dan dapat dinyatakan bahwa ada hubungan positif antara character strength dengan coping stress.

Berdasarkan tabel 12 di atas, dapat disimpulkan dalam penelitian ini diperoleh koefisien determinasi $\mathrm{R}$ Square $\quad\left(R^{2}\right) \quad$ sebesar 0,612 . Berdasarkan hasil tersebut, dapat disimpulkan bahwa sumbangan 61,2 persen character strength mempengaruhi coping stress selebihnya 38,8 persen dipengaruhi oleh faktor lain, seperti konsep diri, kontrol diri, kecerdasan emosional, locus of control, dan kecerdasan spiritual.

Tabel 5.

Korelasi Antara Character Strength dengan Coping Stress

\begin{tabular}{ccc}
\hline Analisis & $\begin{array}{c}\text { Pearson } \\
\text { Correlation }\end{array}$ & $\begin{array}{c}\text { Signifikansi } \\
\text { (p) }\end{array}$ \\
\hline Korelasi & 0,783 & 0,000 \\
\hline
\end{tabular}

Hasil penelitian pada 151 orang pasien Loka Rehabilitasi BNN Deli Serdang menunjukkan bahwa ada hubungan positif antara character strength dengan coping stress, dengan koefisien korelasi Product Moment (Pearson Correlation) sebesar 0,783 dan nilai p sebesar 0,000 ( $p<0,05)$. Berdasarkan nilai tersebut, artinya semakin tinggi character strength yang dimiliki seorang individu, maka semakin tinggi coping stressnya, dan sebaliknya semakin rendah character strength yang dimiliki seorang individu, maka semakin rendah coping stressnya.

Hasil penelitian ini sejalan dengan yang dikemukakan oleh Rasmun (2004) 
yang menyatakan bahwa coping stress sebagai suatu proses yang dilalui oleh individu dalam menyelesaikan situasi stressful. Coping stress tersebut adalah merupakan respon individu terhadap situasi yang mengancam dirinya baik fisik maupun psikologi. Berdasarkan penjelasan ahli di atas, dapat diketahui bahwa terdapat hubungan antara character strength dengan coping stress.

Berdasarkan penjelasan di atas dapat disimpulkan bahwa karakter positif yang dimiliki oleh pasien, dapat membantu para pasien dalam menghadapi berbagai situasi dan tekanan yang muncul selama proses rehabilitasi di Loka Rehabilitasi BNN Deli Serdang. Merujuk dari pemaparan tersebut, maka dapat dikatakan bahwa ada hubungan positif antara character strength dengan coping stress yang dimiliki oleh para pasien selama menjalani rehabilitasi di Loka Rehabilitasi BNN Deli Serdang. Artinya, semakin tinggi tingkat character strength yang dimiliki para pasien, maka semakin tinggi pula coping stress. Sebaliknya, semakin rendah tingkat character strength yang dimiliki para pasien, maka semakin rendah pula coping stress.

\section{SIMPULAN}

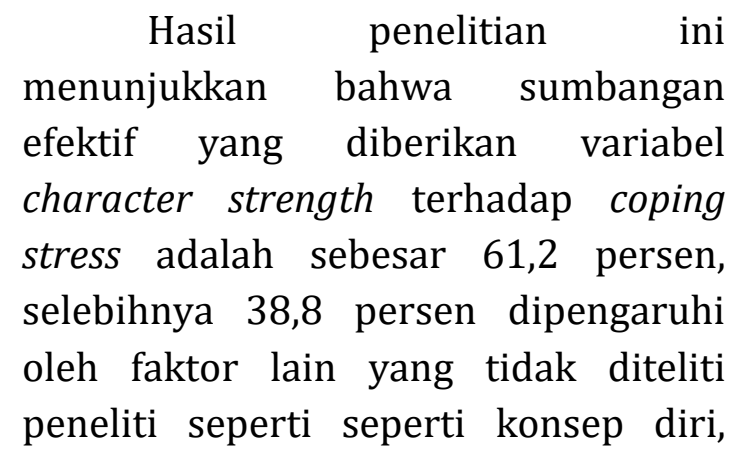

kontrol diri, kecerdasan emosional, locus of control, dan kecerdasan spiritual.

\section{UCAPAN TERIMAKASIH}

Terimakasih kepada pihak Loka Rehabilitasi Badan Narkotika Nasional Deli Serdang Badan Narkotika Nasional yang telah memberi dana dalam mendukung penyelesaian penelitian ini.

\section{DAFTAR PUSTAKA}

Brannon, L., \& Feist, J. (200o). Health Psychology: An Introduction to Behavior and Health (4th ed.). Wadsworth/Thomson Learning. https://psycnet.apa.org/record/20o1o6878-00o

Chaplin, J. P. (2002). Kamus Lengkap Psikologi. Jakarta: Rajawali Pers.

Greenstein, M., \& Holland, J. (2014). Lighter as We Go: Virtues, Character Strengths, and Aging. New York: Oxford University Press.

Harzer, C., \& Ruch, W. (2015). The Relationships of Character Strengths with Coping, Work- Related Stress, and Job Satisfaction. Original Research Article, 6. https://www.ncbi.nlm.nih.gov/pmc/articl es/PMC4341515/

Kim, J. H., Reid, C. A., McMahon, B. T., Gonzalez, R., Lee, D., \& Keck, P. (2016). Measuring The Virtues and Character Traits of Rehabilitation Clients: The Adapted Inventory of Virtues and Strengths. Journal of Occupational Rehabilitation, $\quad 26, \quad 32-44$. https://www.researchgate.net/publicatio n/289366967_Measuring_the_Virtues_an d_Character_Traits_of_Rehabilitation_Cli ents_The_Adapted_Inventory_of_Virtues _and_Strengths

Kominfo.go.id. (2015). BNN Ingatkan 50 Orang Meninggal Setiap Hari Karena Narkoba. Kominfo.Go.Id.

https://kominfo.go.id/index.php/content /detail/4883/BNN+Ingatkan+5o+Orang+ Meninggal+Setiap+Hari+karena+Narkoba /o/sorotan_media

Nevid, J. S., Rathus, S. A., \& Greene, B. (2005). 
Psikologi Abnormal. Jakarta: Erlangga.

Peterson, C., \& Seligman, M. E. P. (2004). Character Strength and Virtues: A Handbook and Classification. New York: American Psychological Association.

Polly, S., \& Britton, K. (2015). Character Strengths Matter: How to Live a Full Life. https://doi.org/LLC

Sarafino, E. P., \& Smith, T. W. (2008). Health Psychology, Byopsychosocial Interactions. New York: John Wiley \& Sons Inc.

Simmons, C. (2012). Tools for Strengths-Based Assessment and Evaluation. New York: Springer Publishing Company.

Smith, R. E., Schutz, R. W., Smoll, F. L., \& Ptacek, J. (1995). Development and Validation of a Multidimensional Measure of Sport-Specific Psychological Skills: The Athletic Coping Skills Inventory-28. JOURNAL OF SPORT E EXERCISE PSYCHOLOGY, 17, 379-398. https://www.researchgate.net/publicatio n/232496845_Development_and_Validati on_of_a_Multidimensional_Measure_of_ Sport-Specific_Psychological_Skills_The_ Athletic_Coping_Skills_Inventory-28

Stallard, P. (2005). Children's Guide to Think Good-Feel Good. London: British Library of Cataloguing Publication Data.

Sugiyono. (2010). Metode Penelitian Kuantitatif Kualitatif dan RED. Bandung: Alfabeta.

Wicaksana, I. (2008). Mereka Bilang Aku Sakit Jiwa. Yogyakarta: Kanisius.

Won, L. (2011). The Adaptive Nature Of The Strengths Of The Youth A Sense Of Hi Effect Of Coping. The Korean Journal of Health Psychology, 16 (1151-167). http://www.kci.go.kr/kciportal/landing/a rticle.kci?arti_id=ARToo1542225 